\title{
Outcome of Breast Cancer Surgery in a Selected Specialized Hospital in Dhaka City, Bangladesh
}

\author{
Mahabuba Afrin ${ }^{1}$, Md Nahid Uz Zaman ${ }^{2,}$ * \\ ${ }^{1}$ Intensive Care Unit, Shaheed Suhrawardy Medical College \& Hospital, Dhaka, Bangladesh \\ ${ }^{2}$ Department of Casualty, Rajshahi Medical College Hospital, Rajshahi, Bangladesh
}

Email address:

mahabuba.a32@gmail.com (M. Afrin),nuz1192@gmail.com (Md N. Uz Zaman)

${ }^{*}$ Corresponding author

\section{To cite this article:}

Mahabuba Afrin, Md Nahid Uz Zaman. Outcome of Breast Cancer Surgery in a Selected Specialized Hospital in Dhaka City, Bangladesh. Cancer Research Journal. Vol. 5, No. 3, 2017, pp. 20-23. doi: 10.11648/j.crj.20170503.11

Received: November 14, 2017; Accepted: November 24, 2017; Published: January 4, 2018

\begin{abstract}
This descriptive type of cross sectional study was conducted to Outcome of breast cancer surgery in a selected specialized hospital in Dhaka city with a sample size of 120. It was found that most of the participants in age group 41-55 years $74.2 \%$ followed by $>55$ years $13.3 \%,<6.7$ years $6.7 \%$ and $26-40$ years $5.8 \%$ respectively with Mean age $48.36 \pm 9.089$ years. Revealed that half of the respondents (52.5\%) educational level were secondary followed by $20.8 \%$ were higher secondary, $15 \%$ were primary, $6.7 \%$ were graduate \& above and only 5\% were illiterate respectively. Most of the respondents (80\%) occupations were housewife and rests of them $20 \%$ were service/ employee respectively. It was found that $63.3 \%$ monthly family income of the respondents were BDT $15001-30000$ belonged to $22.5 \%$ were BDT $30001-45000$, $10.8 \%$ were $<15000$ and $3.3 \%$ were $>45000$ respectively. Showed that most of the respondents $(77.5 \%)$ had mental stress and rest of them $22.5 \%$ did not. Revealed that most of the respondents $(79.2 \%)$ breastfeed all the child were all children and rest of them $20.8 \%$ were maximum child respectively. Showed that most of the respondents $(80 \%)$ were thinking have financial problem and rest of them $20 \%$ been done not. Revealed that half of the respondents $(56.7 \%)$ were did not breast biopsy or surgery and rest of them $43.3 \%$ were had. A highly significant association between age and socio-demographic of the respondents $(\mathrm{P}$ value= $0.000)$. Showed that there is a significant association between occupation and socio-demographic of the respondents $(\mathrm{P}$ value $=$ $0.003)$.
\end{abstract}

Keywords: Outcome, Breast Cancer, Surgery, Dhaka City, Bangladesh

\section{Introduction}

Breast cancer in women is a major health burden. It is the most common cause of cancer death among women in both high recourse and low recourse countries. The incidence, mortality and survival rate in different parts of the world vary from 4 to 10 fold. Recent global cancer statistics indicate that breast cancer incidence is rising at a faster rate in populations of developing countries [1]. The incidence of breast cancer in Bangladesh seems to be very high. As we do not have any cancer registry with relevant data about age, sex, marital status, different types of cancers, diagnostic \& treatment status and survival \& mortality rate of cancer patients it is difficult to say the exact situation in Bangladesh. That is one reason why policy makers are not able to concentrate on this fast growing problem. However, it is easily predictable that the incidence of breast cancer is growing at a faster rate and that the overall situation is not promising. The recent fall of death from breast cancer in western nations is particularly explained by earlier diagnosis as a result of early presentation [2]. In most of the developing countries including Bangladesh patient comes for treatment in an advance stage when little or no benefit can be derived from any sorts of therapy. Early diagnosis can be successfully achieved by mass screening either by Mammography, Clinical Breast Examination (CBE) and Self breast examination (SBE) or by the combination of three. Though it is well documented that mammography is the best choice for screening, breast self- 
examination is also equally important and beneficial for mass awareness especially in country with limited recourses. In a developing country like Bangladesh and it is not a realistic approach to pursue a population based mass screening program According to stepwise approach of Global Summit Panel 2002 [3]. Breast Self-Examination would be the approach for early detection in limited resources countries. Preventive behavior is essential for reducing cancer mortality. Knowledge is a necessary predisposing factor for behavioral change. Knowledge also plays an important role in improvement of health seeking behavior. Not only that knowledge might dramatically improve the attitude, disbelieve, and misconception and consequently enhance screening practice. That's why to reduce the number of deaths from breast cancer, there was a shift in emphasis from breast self-examination to breast awareness after 1991 [4]. Beside this, several studies also show that knowledgeable women are more likely to adhere to recommended breast cancer screening [5]. This research effort will find out the outcome of breast cancer treatment in Bangladesh. But the findings will be from only one hospital. Which is likely to encourage other researcher to carry out fruitful studies on assessing the treatment out come in other centers. The result may be hallmark for the oncologist to adopt a right course of treatment availing modern technology for the benefits of the patients.

\section{Materials \& Method}

The descriptive cross sectional was used to explore the Outcome of Breast Cancer Surgery in a Selected Specialized Hospital in Dhaka City, Bangladesh. The study was conducted at United Hospital Ltd, Dhaka. Study population are all breast cancer patients undergoing breast surgery in Dhaka city and Sample population are Patient having breast surgery at least before six months in United hospital. The study was carried out from January 2014 to April 2014. But due to time constraint only a sample of 120 was included in the study with the kind consent of the guide.

\section{Results}

It was found that among 120 study respondents most of the participants in age group 41-55 years $74.2 \%$ followed by $>55$ years $13.3 \%,<6.7$ years $6.7 \%$ and $26-40$ years $5.8 \%$ respectively with Mean age $48.36 \pm 9.089$ years. Half of the respondents $(52.5 \%)$ educational level were secondary followed by $20.8 \%$ were higher secondary, $15 \%$ were primary, $6.7 \%$ were graduate \& above and only $5 \%$ were illiterate respectively. Most of the respondents (80\%) occupations were housewife and rest of them $20 \%$ were service/ employee respectively. It was found that $63.3 \%$ monthly family income of the respondents were BDT 1500130000 belonged to $22.5 \%$ were BDT $30001-45000,10.8 \%$ were $<15000$ and $3.3 \%$ were $>45000$ respectively.
Table 1. Distribution of the respondents by age.

\begin{tabular}{lll}
\hline Age (years) & Frequency & Percentage (\%) \\
\hline$<25$ & 8 & 6.7 \\
$26-40$ & 7 & 5.8 \\
$41-55$ & 89 & 74.2 \\
$>55$ & 16 & 13.3 \\
Total & 120 & 100.0 \\
\hline
\end{tabular}

Mean $\pm \mathrm{SD}=48.36 \pm 9.089$

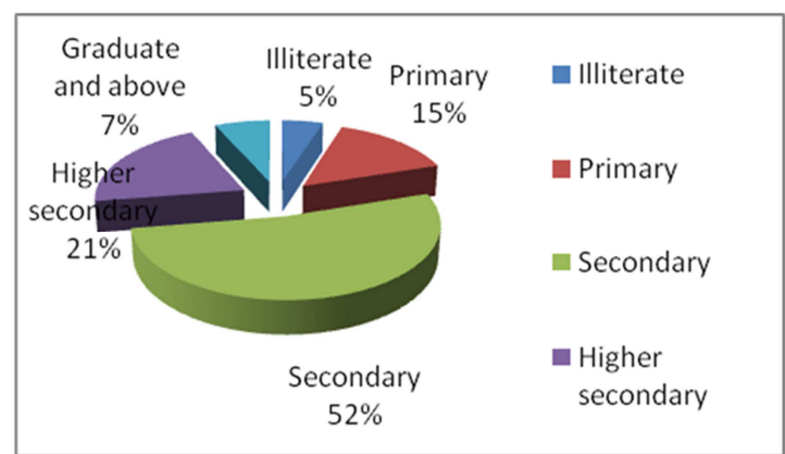

Figure 1. Distribution of the respondents by educational qualification

Table 2. Distribution of the respondents by occupation.

\begin{tabular}{lll}
\hline Occupation & Frequency & Percentage (\%) \\
\hline Service/Employee & 24 & 20.0 \\
House wife & 96 & 80.0 \\
Total & 120 & 100.0 \\
\hline
\end{tabular}

Table 3. Distribution of the respondents by monthly family income.

\begin{tabular}{lll}
\hline Monthly income (BDT) & Frequency & Percentage (\%) \\
\hline$<15000$ & 13 & 10.8 \\
$15001-30000$ & 76 & 63.3 \\
$30001-45000$ & 27 & 22.5 \\
$>45000$ & 4 & 3.3 \\
Total & 120 & 100.0 \\
\hline
\end{tabular}

Most of the respondents (79.2\%) breastfeed all the child were all children and rest of them $20.8 \%$ were maximum child respectively.

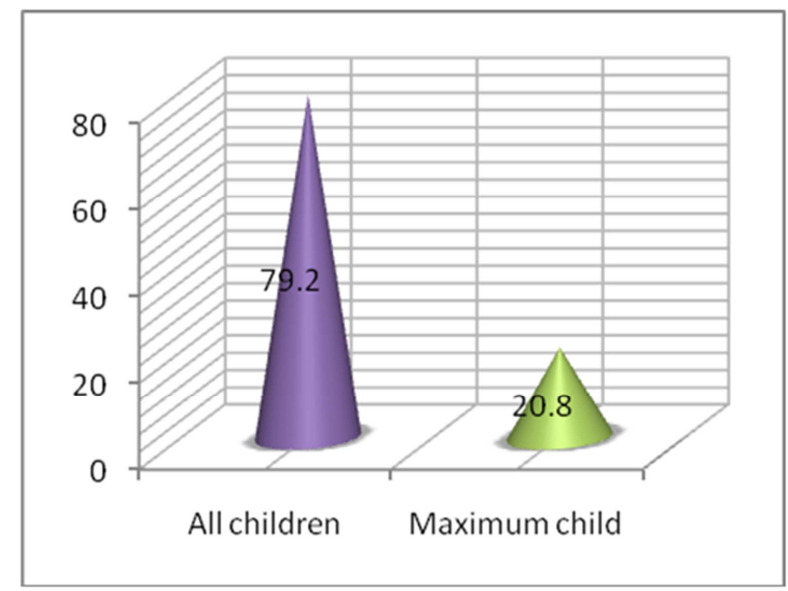

Figure 2. Distribution of the respondents by breastfeed all the child.

Most of the respondents $(80 \%)$ were thinking have financial problem and rest of them $20 \%$ were did not. 


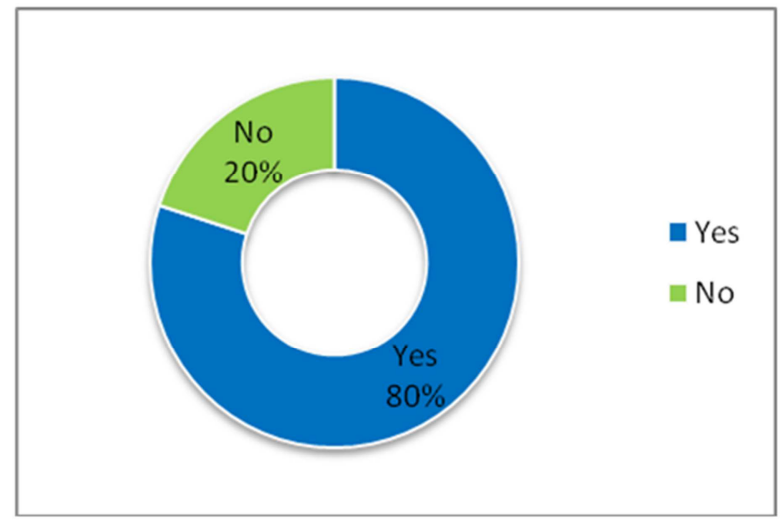

It reveals that half of the respondents $(56.7 \%)$ were did not breast biopsy or surgery and rest of them $43.3 \%$ were had.

Table 4. Distribution of the respondents by any history of breast biopsy or surgery.

\begin{tabular}{lll}
\hline Variables & Frequency & Percentage (\%) \\
\hline Yes & 52 & 43.3 \\
No & 68 & 56.7 \\
Total & 120 & 100.0 \\
\hline
\end{tabular}

It reveals that there is a highly significant association between age and socio-demographic of the respondents ( $\mathrm{P}$ value $=0.000)$.

Figure 3. Distribution of the respondents by have financial problem.

Table 5. Distribution of the respondents by association between age and socio demographic of the respondents.

\begin{tabular}{llllll}
\hline \multirow{2}{*}{ Do you have mental stress } & \multicolumn{2}{l}{ Age in years } & & & \multirow{2}{*}{ Total } \\
\cline { 2 - 5 } & $<\mathbf{2 5}$ Years & $\mathbf{2 6 - 4 0}$ Years & $\mathbf{4 1 - 5 5}$ Years & $>\mathbf{5 5}$ Years & 93 \\
\hline Yes & 5 & 1 & 76 & 11 & 27 \\
No & 3 & 6 & 13 & 5 & 0.000 \\
Total & 8 & 7 & 89 & 16 & 120 \\
\hline
\end{tabular}

It shows that there is a significant association between occupation and socio-demographic of the respondents $(\mathrm{P}$ value= $0.003)$.

Table 6. Distribution of the respondents by association between occupation and socio demographic of the respondents.

\begin{tabular}{lllll}
\hline \multirow{2}{*}{ Do you have mental stress } & Occupation of the respondents & Total & \multirow{2}{*}{ P-value } \\
\cline { 2 - 4 } & Service/Employee & House wife & 93 \\
Yes & 24 & 69 & 27 \\
No & 0 & 27 & 120 & 0.003 \\
Total & 24 & 96 & 27 \\
\hline
\end{tabular}

\section{Discussion}

Many studies showed that worldwide, breast cancer is twelfth most common and the fifth most deadly cancer in women [6] A study of History of sentinel node and validation of the technique reveals that 16 per 100,000 women per year and kills about 9 per 100,000 per year [7] Approximately $80 \%$ of breast cancers occur in developing countries. Worldwide, in 2008 , it was estimated that there were 473,000 cases of breast cancer, and 253,500 deaths per year [8]. A study conducted in the United States reported it as the 8th most common cancer of women. Another study shows that in 1998, about 12,800 women were diagnosed in the US and among them about 4,800 died. The incidence and mortality in the US are about half those for the rest of the world, which is due in part to the success of screening with the Pap smear [9]. Another study reveals that in 2008 in the US an estimated 11,000 new cases were expected to be diagnosed, and about 3,870 were expected to die of breast cancer among gynecological cancers it ranks behind endometrial cancer and ovarian cancer [10]. Study conducted in USA further revealed that the incidence of new cases of breast cancer in the United States was 7 per 100,000 women in 2004 [11].

\section{Conclusion}

Breast cancer is a dangerous disease which may lead to death if untreated early enough. That is why breast cancer is extremely important for effective treatment as well as breast cancer prevention. It may be appropriate in women who have a particularly high risk of developing Breast cancer. Nevertheless, this education was not effective in increasing the awareness of these women about breast cancer, probably because it was not designed to provide useful health information about this menace. Young educated women knew about breast cancer as much as the older uneducated women. This underlines the importance of basic health education at all age levels. The major reasons why women do not perform breast cancer are their lack of knowledge on how to do it and lack of belief in its necessity.

\section{References}

[1] Bray F, Mac Carron P, and D Maxwell Parkin: The changing global patterns of female breast cancer incidence and mortality, Breast cancer Res 2004, 6: 229-239.

[2] Parkin DM, Whelan SL, Ferlay J, Raymond L, Young J: Cancer Incidence in Five Continents, vol VIII. Lyon: IARC Press; 1997. 
[3] Benjamin OA, Susan Braun, Susan Lim, Robert AS, Stephen $\mathrm{T}$ and et al. Early detection of breast cancer in countries with limited resources. The breast Journal 2003, 9: S51-S59.

[4] English J.: Importance of breast awareness in identification of Breast cancer. Nursing Times 2003, 99(40) 18-9.

[5] Georgia R Sadler and al el Breast cancer knowledge, attitudes, and screening behaviors among African American women: the Black cosmetologists promoting health program. BMC Public Health 2007, 7: 57.

[6] Mansel RE, Fallowfield L, Kissin M, et al. Randomized multicen- ter trial of sentinel node biopsy versus standard axillary treatment in operable breast cancer: the ALMANAC Trial. J Natl Cancer Inst 2006; 98: 599-609.

[7] Jacobson JA, Danforth DN, Cowan KH, et al. Ten-year results of a comparison of conservation with mastectomy in the treatment of stage I and II breast cancer. N Engl J Med 1995; 332: 907-911.

[8] Chagpar AB, Martin RC, Scoggins CR, et al. Factors predicting failure to identify a sentinel lymph node in breast cancer. Surgery 2005; 138: 56-63.

[9] McMasters KM, Wong SL, Chao C, et al. Defining the optimal surgeon experience for breast cancer sentinel lymph node biopsy: a model for implementation of new surgical techniques. Ann Surg 2001; 234: 292-300.

[10] Wong L P, Wong Y L, Low W Y, Khoo E M, Shuib R. Knowledge and awareness of cervical cancer and screening among Malaysian women who have never had a Pap smear: a qualitative study. Singapore Med J 2009; 50 (1): 49.

[11] World Health Organization (February 2006). "Fact sheet No. 297: Cancer". Retrieved 2007-12-01. 